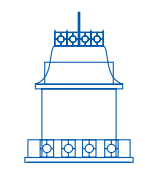

PRESENTACIÓN

\title{
30 años de Estudios de Filosofía
}

La revista Estudios de Filosofía nació en 1990 en lo que era el Departamento de Filosofía y que luego se transformó en el Instituto de Filosofía de la Universidad de Antioquia. Su fundador y primer director fue el profesor Jairo Alarcón Arteaga. Además, el primer comité editorial estaba conformado por Jorge Antonio Mejía Escobar, Javier Domínguez Hernández, Jorge Montoya Peláez y Gustavo Valencia Restrepo. En el número 10 de la revista se creó el primer comité científico, que en ese momento se llamó "comité internacional", y estaba conformado originalmente por Miguel Giusti, José María González, Pablo de Greiff, Axel Honneth y Friedrich Kambartel.

Al inicio la revista fue un espacio para difundir y discutir principalmente el trabajo investigativo de los profesores de esta institución; por ello, los artículos de los primeros números eran mayoritariamente de los profesores de la UdeA o traducciones que ellos hacían de textos de profesores extranjeros. Esto evidencia que la investigación ha sido el elemento estructurador del Instituto desde sus inicios y ha repercutido en la calidad de la docencia y en la creación de nuevo conocimiento. Sin embargo, lentamente la revista fue ampliando su alcance y, a continuación, la revista empezó a atraer artículos de profesores de otras universidades colombianas.

Por esta misma época, la revista empieza a incluir cada vez más artículos de autores de otras latitudes y, en varios casos, compilaciones de artículos temáticos producto de los congresos internacionales de filosofía que se empezaron a realizar en el Instituto. Cabe resaltar algunos de los profesores internacionales destacados que publicaron sus artículos en la revista: Adela Cortina, Karen Gloy, Gilvan Fogel, Félix Duque, Manfred Kerkhoff, Miguel Giusti, María Isabel Santa Cruz, José Luis Villacañas, Klaus Vieweg, Úrsula Wolf, Ernst Tugendhat, Martha Nussbaum y Galen Strawson, entre otros.

Hoy la revista tiene un enfoque aún más amplio y pretende ser una plataforma internacional de discusión y difusión de las investigaciones contemporáneas. Por ello, desde hace un par de números hemos incluido artículos en inglés, ya que esto nos abre a otros públicos y a otros debates en filosofía.

Recientemente, la revista llevó un proceso de autoevaluación que le permitió detectar algunas falencias y diseñar un plan de mejoramiento. Algunos de los cambios 
que ya se habían reseñado en estas páginas, pero que vale la pena volver a resaltar, son la actualización del comité editorial y científico, la creación de nuevos formatos de evaluación en línea, el uso del OJS (Open Journal System) como herramienta de gestión editorial y, el ingreso a DOAJ (Directory of Open Access Journals) y REDIB (Red Iberoamericana de Innovación y Conocimiento).

Ahora, para celebrar los 30 años de la revista, hemos implementado nuevos cambios que mejorarán la revista en diversos aspectos. Primero, hemos actualizado la página web de la revista: hoy se puede consultar información actualizada y ordenada en español y en inglés. Segundo, hemos subido todos los archivos PDF de los números completos y de todos los artículos individuales que se han publicado hasta hoy. Tercero, hemos completado todos los metadatos de todos los artículos que se han publicado. Este detalle no lo ve el lector a simple vista, pero es el elemento fundamental que le permite a los lectores encontrar nuestros artículos usando buscadores de Internet. Cuarto, hemos subido las versiones HTML de artículos de varios de los últimos números, y el plan es continuar subiendo estas versiones de los números anteriores. La versión HTML ofrece un formato que se adapta fácilmente a consultas desde computador y teléfonos móviles sin necesidad de descargar el archivo. Quinto, hemos montado los metadatos de todos los artículos en Google Scholar. Esto también le dará más visibilidad a la revista. Sexto, hemos montado la mayoría de los artículos de autores de la UdeA al repositorio institucional.

Finalmente, el cambio más destacado de la revista tiene que ver con su diseño. Decidimos cambiar la carátula de la revista y volver a un diseño cercano al de los primeros números al incluir la imagen del Paraninfo de la Universidad de Antioquia. En esta edificación, ubicada en la plazuela de San Ignacio de Medellín, inició labores esta institución educativa en 1803. También decidimos cambiar el diseño interno de las páginas de la revista e incluir nuevos elementos que responden a las nuevas dinámicas de la revista; en particular, el hecho de que la mayoría de nuestras consultas se hagan a través del Internet. Así, lo primero que incluimos fue el logo del Paraninfo en las primera páginas de cada artículo para darle identidad a los artículos consultados de manera independiente a través de la web. Luego, incluimos color para hacer el texto más amable al ojo. También incluimos hipervínculos a la página de la revista y a los textos referenciados para que el lector pueda encontrarlos y consultarlos más fácilmente.

Para cerrar este mensaje de celebración es fundamental recordar que a lo largo de estos años varios profesores del Instituto han contribuido en la dirección de la revista: Jairo Alarcón Arteaga, quien además fue fundador, Javier Domínguez, Lucy Carrillo, Carlos Vásquez y Francisco Cortés. También hay que resaltar la labor del profesor Jorge Antonio Mejía, como editor de la revista desde el primer número, y de Carmen Elena Muñoz, quien ha estado apoyando los procesos de edición de la revista a lo largo de estos años. Sea este el momento de agradecerles a todos por su trabajo y esfuerzo.

Santiago Arango Muñoz

Director

Estudios de Filosofía

https://doi.org/10.17533/udea.ef.n61a01 


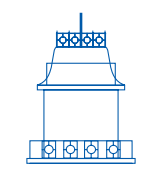

PRESENTACIÓN

\section{Heidegger en el siglo XXI}

Martin Heidegger es, sin lugar a duda, uno de los pensadores más representativos e influyentes del siglo XX. Fue compañero de camino y de debate de autores como Husserl, Scheler o Jaspers; maestro directo e influencia insoslayable de Arendt, Löwith, Jonas, Marcuse, Levinas, Strauss, Gadamer y otros; renovador e impulsor de los movimientos fenomenológico y hermenéutico, cuya huella se aprecia además en los proyectos de Merleau-Ponty, Patočka, Ricoeur, Habermas, Vattimo y Derrida; fuente de inspiración del existencialismo francés y español (Sartre, de Beauvoir, Zubiri, Ortega y Gasset), de la escuela de Kyoto y del pensamiento latinoamericano (Dussel, Gaos, Astrada); punto de partida y motivo de reflexión de muchos otros, como Foucault, Lacan, Rorty, Nancy, Marcel, Henry, Dreyfus, Sloterdijk, Han etc.

Su extensa obra - planeada en 102 volúmenes y todavía en curso de publicaciónaborda los principales tópicos de la tradición filosófica occidental, debate con las figuras más importantes de la misma (desde los presocráticos hasta Nietzsche) y ofrece una interpretación integral de su sentido: la filosofía, según nos dice, es historia de la metafísica y del olvido del ser. Los efectos de su trabajo se extienden a ámbitos de reflexión tan diversos como la teología, la teoría de la arquitectura, la psicoterapia, la ecología y el medio ambiente, la técnica y la tecnología, y las ciencias cognitivas, por mencionar solo algunos. Ya sea para inspirarse de él y desarrollar aspectos de su filosofía, ya sea para discutirla críticamente o para rechazar tajantemente sus planteamientos, su filiación política o su extraño y polémico uso del lenguaje, es claro que se trata de un pensador que no ha dejado indiferente a nadie y frente al cual es todavía necesario situarse.

La amplia recepción de su filosofía muestra ya la pertinencia del tema que aquí nos ocupa. Preguntarse por el pensamiento de Heidegger en el siglo XXI no consiste solamente en debatir el carácter productivo y las posibilidades de desarrollo de su filosofía, o los límites de ésta y la necesidad de avanzar en otras direcciones, sino que implica sobre todo poner en cuestión nuestra propia situación histórica y filosófica, para tratar de precisar algunos de los temas de reflexión y los interrogantes que han de acompañarnos en lo sucesivo. Heidegger fue, sin duda alguna, el primero que quiso 
evitar que su trabajo cayese en la repetición vacía de fórmulas que han perdido el sentido. Su falta de lenguaje (Sprachnot) para lo que quería decir -como solía llamarla Gadamer- y el forzamiento de muchas de sus articulaciones conceptuales resultan de su constante esfuerzo por dar cuenta de los asuntos mismos y por encontrar el tono adecuado para ellos. Su interés no estaba dirigido a convertir a sus alumnos y al público en general en "heideggerianos", sino en promover el pensamiento autónomo, las preguntas auténticas y la confrontación directa con las cosas mismas. El que haya orientado su filosofía hacia "lo único digno de ser pensado" y el que haya desarrollado bajo esta idea -y de forma casi siempre unilateral- su apropiación de los autores de la tradición no deben ser interpretados como intentos de limitar el pensamiento, sino como esfuerzos por remitir los más diversos fenómenos a lo que él consideraba constituye la fuente originaria del sentido y del darse mismo de todo ente en un acontecer que supera lo meramente dado. Heidegger era plenamente consciente del carácter relativo de su propia filosofía dentro del conjunto de la historia y del hecho de que el "nuevo pensar" - que él intentaba, con todas sus fuerzas, preparar- no habría de venir propiamente de él. Por eso, hoy podemos volver a preguntarnos con él hacia dónde se orienta nuestro propio camino del filosofar.

El presente número de Estudios de Filosofía ofrece a sus lectores un bouquet de trabajos, en el que se tratan de manera renovada tanto temas considerados clásicos en los estudios heideggerianos, como aspectos relativamente recientes y novedosos en la lectura de este autor. De manera diversa y bajo diferentes perspectivas, los colaboradores de la revista se ocupan de examinar, entre otros, el problema ineludible de la articulación de los dos grandes momentos del pensamiento de Heidegger; las implicaciones metódicas y las necesidades expresivas que surgen del pluralismo ontológico y de la llamada "diferencia ontológica"; la experiencia del tiempo, de la historia y la toma de conciencia de la propia finitud; el sentido de la filosofía en la época de la técnica y la posibilidad de una superación de la metafísica; y los aportes de los planteamientos de Heidegger a los debates recientes sobre la naturaleza, el cuerpo, lo animal y el "posthumanismo". Cierran el volumen dos reseñas de trabajos recientes que responden, cada uno a su manera, a la pregunta que aquí se ha querido plantear. El primero trata sobre la relación del pensamiento de Benjamin con el de Heidegger; el segundo, sobre la cuestión de la técnica. Visiblemente, nos encontramos frente a un autor cuya "historia efectual" (Wirkungsgeschichte) no ha cesado aún y cuya relación con otras corrientes de pensamiento aún necesita ser explorada. De seguro, el lector encontrará aquí elementos que contribuyan a su trabajo, que ayuden a comprender la filosofía de Heidegger y que le permitan plantear sus propias preguntas y seguir avanzando en las respuestas.

Aunque el propio Heidegger consideraba que ninguno antes de él había todavía preguntado, con suficiente radicalidad, por el problema del ser, del sentido y de su acontecer, también era consciente del hecho de que su pensamiento, más allá de su gran fuerza e indudable originalidad, no habría sido posible sin el concurso de 
quienes estuvieron antes, en ese diálogo secreto que -según él mismo dice- los grandes pensadores mantienen entre sí a través de la historia. Esto mismo ocurre con nosotros, quienes ahora recibimos esta herencia intelectual y quienes tenemos la responsabilidad de hacer, por nosotros mismos, algo con ella.

Sea éste el momento de felicitar a la revista Estudios de Filosofía por sus treinta años de labor y de exaltar la labor callada, modesta y generosa de su fundador, el profesor José Jairo Alarcón Arteaga, fallecido ya, quien puso en marcha este proyecto en 1990 y sobre cuyo trabajo inicial avanzamos hoy quienes hacemos parte del Instituto de Filosofía de la Universidad de Antioquia. Muchos han sido los autores de todos los países que han publicado y difundido sus trabajos de investigación en este lugar; muchos también, los lectores y beneficiarios de esta noble labor. Un especial reconocimiento a las personas que durante estos treinta años hicieron posible este proyecto. A sus sucesivos directores, editores, asistentes, traductores, correctores, diagramadores y miembros del comité editorial: ¡Bravo!

Andrés F. Contreras

Editor invitado

Instituto de Filosofía

Universidad de Antioquia

https://doi.org/10.17533/udea.ef.n61a02 